\title{
Gender differences and factors affecting publication productivity among Australian university academics
}

\author{
Peter Bentley \\ LH Martin Institute, The University of Melbourne \\ E: pbentley@unimelb.edu.au
}

\begin{abstract}
This article examines gender differences in publication productivity and factors correlated with high productivity in Australian universities, during the periods 1991-93 and 2005-2007. Measured as a weighted sum of books and journal articles, females reported significantly fewer publications than men during both periods. Gender differences appear to have reduced over time, with female publishing increasing from 57 percent of the male average in 1991-1993 to 76 percent in 2005-2007. Statistical analyses reveal that women published at similar levels to men of equal rank during both periods, except among Level A staff in 1991-1993 where males published significantly more. Academic rank, doctorate qualifications, research time and international research collaboration were the strongest factors positively associated with publication productivity, but women typically reported significantly lower levels on each of these factors. Institutional and family characteristics were comparably poor predictors.
\end{abstract}

Key words: gender, higher education, academic profession, research.

The Australian academic profession underwent dramatic changes over the past quarter of a century. The Dawkins reforms of the late 1980s, new public management and marketisation, profoundly affected the research orientation and gender profile of Australian universities. The proportion of female academics more than doubled between 1985 and 2010, from 21.6 to 43.6 percent (Carrington and Pratt, 2003; DEEWR, 2010). Over the same period, the proportion of senior ranking positions held by women (above Level C/Senior Lecturer) also increased from 6.0 to 26.7 percent. The growing numbers of female academics has been partly attributed to the Dawkins reforms, which removed the binary divide between universities and former teaching-oriented, vocational 'colleges of advanced education' (CAEs) (Carrington and Pratt, 2003). While the proportion of women was only marginally higher in CAEs compared to the pre-1987 universities (Bell and Bentley, 2005), the unification broadened the disciplinary base of universities by incorporating non-traditional disciplines where women held a critical mass but had weaker research traditions, such as teacher training and nursing. However, despite well established equal employment opportunity legislation and affirmative action frameworks, women have remained overrepresented in junior ranks and underrepresented in science-related disciplines (Allen and Castleman, 2001; White, 2003).

The 'vertical segregation' of women in lower ranks and 'horizontal segregation' by discipline has received considerable attention (Carrington and Pratt, 2003). The precedence of research performance in promotional decisions is frequently cited as a barrier to improved gender

The final, definitive version of this paper has been published in Journal of Sociology, 48(1), pp.85103. by SAGE Publications Ltd, All rights reserved. (c) [ http://jos.sagepub.com/content/48/1/85] 
equity. The academic hierarchy arguably institutionalises male dominance by associating merit primarily with research publishing, an activity which males receive greater patronage and support (Burton, 1997). Female doctoral students report significantly less encouragement to publish, to apply for research funding, to present research at conferences and to collaborate on research projects (Dever, et al., 2008). This forces women to play 'catch up' later in their careers (Symonds et al., 2006) and likely has negative long term and cumulative career consequences (Long et al., 1993). White (2001) also contends that women have less interest in research and are concentrated in positions with heavier teaching loads. The deeper implementation of new public management in lower ranks also undermines equal employment opportunity legislation by entrenching the gendered character of university power relations (Lafferty and Fleming, 2000). The concentration of external research funding in science-based and male-dominated disciplines, further hampers female research opportunities (Bell and Bentley, 2005).

Despite its perceived importance, surprisingly few multi-disciplinary Australian studies have examined the publication productivity of men and women, or factors associated with stronger publication records. Sheehan and Welch (1996) found women were less likely than men to publish books, articles, reports and conference papers. Asmar (1999) found early career females were less likely than males to publish as a co-author during their doctorate studies, but equally likely to publish as a sole author. However, both studies only analysed the proportion of men and women publishing, not mean levels of output. Ramsden (1994) examined the factors associated with higher publication productivity and found that women published less than men, but gender had no direct effect after controlling for academic rank. Burton (1997: 24) claims that gender-based comparisons of publication data 'are misleading when not broken down by academic level'. Reviews of institutional reports and earlier studies find few gender differences in publishing above the lowest ranks (Burton 1997; Castleman, et al., 1995). Teodorescu (2000) examined factors associated with article publication productivity and found gender was not significant after controlling for individual-level factors, such as academic rank, research time and research funding. However, none of these aforementioned studies specified the size of gender differences in publishing or whether factors, such as family responsibilities and research collaboration, operate differently for men and women.

\section{Rationale for the study and research questions}

The lack of empirical evidence on gender differences in publishing productivity in Australia raises three questions this article will address:

1. How large are gender differences in publication productivity?

2. Have gender differences in publication productivity changed over time?

3. What factors are associated with increased publication productivity among men and women?

\section{Data}

The data comes from two international surveys: the 1993 Survey of the Academic Profession conducted by the Carnegie Foundation for the Advancement of Teaching (hereafter 
'Carnegie') and the 2007 Changing Nature of the Academic Profession (CAP) survey. The target populations were academic staff in Australian public universities, excluding private and overseas providers. Including partial responses, the Carnegie survey generated a sample of 1,420 respondents (response rate 40 percent), while the CAP survey included 1,252 respondents (response rate 24 percent). Both samples closely represented their target populations, were considered appropriate for national level generalisations and have formed the basis of previous Australian studies (Coates, et al., 2008; Sheehan and Welch, 1996). This study examines a subset of respondents: those who answered the research publication question, reported a full-time contract with at least 30 hours per week, and spent at least one hour per week on both teaching and research. The subset includes 713 men and 327 women in the 1993 Carnegie sample, and 341 men and 292 women in the 2007 CAP sample. The sample distributions by rank and gender are shown in Table 1.

[Table 1 about here]

\section{Methodology and variable summary}

The production function approach treats publication productivity as a function of independent variables (Teodorescu, 2000). Consistent with Fox's (1983) widely cited framework and Teodorescu's earlier study of the Carnegie data, independent variables are classified as background, work habits or institutional variables. Summarised in Table 2, the variables form the basis of the regression analyses for factors affecting publication productivity.

\section{Dependent variable}

Publication productivity is measured as a weighted sum of an individual's self-reported publications during the three years prior to each survey, 1991-1993 and 2005-2007. The three-year reference period is sufficient to accommodate the time lags between research, submission and publication (Fox and Mohapatra, 2007; Kyvik, 1991). However, in the case of the 1993 data, the reference period includes a transitional period for staff formerly employed in teaching-focused CAEs. Publication productivity is expressed in 'article equivalents' and calculated as a weighted average of 'articles or chapters in academic books or journals' (1 point), 'edited books' (2 points) and 'authored books' (5 points). By including multiple publication types and giving heavier weighting to books, the productivity index minimises differences across academic fields and is consistent with previous multidisciplinary studies (Kyvik, 1991; Kyvik and Teigen, 1996; Ramsden, 1994).

Few academics publish nothing, but the majority of research is published by a small minority. As suggested by Fox and Mohapatra (2007), a square root transformation of article equivalents is used to normalise the skewed distribution of article equivalents for linear multiple regression. Separate regression analyses were also conducted using (untransformed) article equivalents as the dependent variable. These analyses achieved comparable results to those with the square root transformation, but with generally lower beta weights, lower coefficients of determination (R-square) and fewer variables achieving significance. Genderbased comparisons of means are computed with an independent samples $t$-test and 95 percent significance level.

The dependent variable has clear limitations. No information is available on the number of co-authors, the publication length, quality or impact through citation counts or peer review. This will favour academics who publish a large number of short, co-authored and non-peer 
reviewed publications. Secondly, non-respondents to the publication productivity question were removed from the sample. Non-respondents likely include many non-publishing staff. Therefore, there may be an overestimation of actual publishing levels in the sample.

\section{Independent variables}

Age is a scale variable based on years of age.

Marital status (CAP only) has three categories: 'single', 'married to an academic' and 'married to a non-academic'. Marriage is considered positive for publication productivity, particularly for men (Kyvik, 1991; Long, 1990). Females also benefit from marriage (Hartley and Dobele, 2009), but the positive effects may be negated by the presence of children (Long, et al., 1993). Men married to comparably educated women have been shown to have lower publication productivity than other married men, which may be due to a more equal distribution of household work (Creamer, 1998). Women are more likely to be married to fellow academics, but such marriages have only moderately positive effects on publication productivity compared with other marriage types (Fox, 2005). This may be due to the effect of being a 'trailing spouse' whose career follows the husband (Sonnert and Holton, 1995).

Number of children living at home (CAP only) has four categories: 'no children', 'one child', 'two children' and 'three or more children'. A review of previous studies shows mixed results for the effect of children on publication productivity (Creamer, 1998), but the effect is typically smaller than work habits and institutional factors (Sax et al., 2002). The negative effect of children for women has been shown to increase with the number of children (Long, 1990), but younger children (under 10 years) affect female publication productivity more negatively than older children (Kyvik and Teigen, 1996).

Child and elder care (CAP only) is a continuous variable based on the number of years respondents had interrupted their employment for child or elder care. The greater frequency and duration of career breaks have been interpreted as a long-term disadvantage for female researchers (Long, et al., 1993).

Doctoral degree is a dichotomous variable based on possession of a doctoral degree. The lack of a doctoral degree amongst female academics in Australia has been identified as a barrier for entry, promotion and opportunities for research time (White, 2004). Females also report less supervisor support during their doctoral studies (Dever, et al., 2008).

Academic rank is a scale variable based on the ordinal ranks from Assistant Lecturer/Level A (1) to Professor/Level E (5). Academic rank is among the strongest predictors of publication productivity (Xie and Shauman, 1998). Australian women and men of identical academic rank publish at similar levels (Burton, 1997; Ramsden, 1994).

Interest in research over teaching is a scale variable based on the ordinal responses for selfreported interest in research over teaching, ranging from: 'primarily in teaching' (1), 'in both, but leaning towards teaching' (2), 'in both, but leaning towards research' (3), and 'primarily in research' (4). It has been argued that women are less interested in research than men (White, 2001), but such claims are disputed in surveys (McInnis, 1999). 
Research collaborators is a dichotomous variable based on whether or not respondents have research collaborators. Collaboration is highly correlated with co-authorship and publication productivity (for a summary see: Katz and Martin, 1997). Collaboration has been shown to be more important for female publication productivity (Kyvik and Teigen, 1996), though earlycareer female researchers in Australia collaborate less (Dever et al., 2008; Asmar 1999). For female post-doctoral researchers, being married increases the likelihood of research collaboration with senior males, but children have the opposite effect (Long, 1990).

International research collaboration is a dichotomous variable based on whether or not respondents have international collaborators. International collaboration is associated with increased publication productivity (Kyvik and Teigen, 1996), but women arguably have weaker international networks and opportunities for international collaboration (Burton, 1997: 108; Cole and Zuckerman, 1984; White, 2001).

International conference participation is a dichotomous variable based on whether or not respondents attended an overseas conference in the previous year. Conference participation is an important correlate of publication productivity in international studies (Teodorescu, 2000), particularly when one is invited to present research (Kyvik and Larsen, 1994). Australian male academics are more likely to be invited to international conferences (Ramsay 1999 in White, 2001: 68; Bazeley 1999 in White, 2004: 230) and spend time on conference organisation (Probert, 2005). However, early-career males and females are equally likely to present research at conferences (Asmar, 1999).

Hours per week on research, teaching and administration are three scale variables based on usual weekly hours during teaching and non-teaching periods. The teaching period is weighted as twice the duration of the non-teaching period. To avoid outlier effects, total working hours are capped at 70 hours. Research hours are a significant predictor of article publishing in Australia (Teodorescu, 2000) and additional teaching and administrative duties may limit time available for research (Milem, et al., 2000). The concentration of women in teaching-focused positions is offered as one reason for women's underperformance in research in Australia (White, 2004). Teaching loads are the most frequently reported factor hindering research, reported by 65 percent of Australian academics and 71 percent of women (McInnis, 1999: 45). Teaching hours have been shown to negatively correlate with publication productivity for Australian academic economists (Fox and Milbourne, 1999), but are insignificant in multi-disciplinary studies (Teodorescu, 2000).

Research funding satisfaction is a scale variable based on ordinal responses regarding satisfaction with institutional research funding, ranging from poor (1) to excellent (5). Almost half of all Australian academics report difficulty obtaining research funding as a barrier to research (McInnis, 1999: 45). Women are horizontally segregated in disciplines with weaker access to industrial and national research priority area funding (Carrington and Pratt, 2003) and female doctoral students receive less encouragement to apply for funding (Dever, et al., 2008). However, women are no less successful than men when applying for Australian Research Council grants (Bell, 2010).

Institutional facilities is a scale variable based on a composite of six Likert-type items assessing the adequacy of laboratories, research equipment, computer facilities, library holdings, faculty offices, and secretarial support. The Carnegie survey measured the items using a four-point ordinal scale, while the CAP survey used a five-point scale. The six scores 
were summed and then divided by the number of questions answered, with the resulting score ranging from poor (1) to excellent (4 or 5).

Collegial support for research (CAP only) is a scale variable based on the response to the statement 'At my institution there is collegial support for my research', ranging from 'strongly disagree' (1) to 'strongly agree' (5). Women acknowledge and place a greater importance on collegial and supervisor support, even though they may receive less support overall (Sonnert and Holton, 1995: 140-1; Dever, et al. 2008).

University group (CAP only) includes four dichotomous variables based on the respondent's university institutional grouping: 'Group of 8' (Go8); 'Innovative Research Universities' (IRU), 'Australian Technology Network of Universities' (ATN) and 'other'. The Go8 universities receive almost double the research funding of the other 31 universities combined (DEEWR, 2008: 44), and with the University of Tasmania, were also responsible for roughly two thirds of total research publications in the ISI Web of Science and Scopus indexes between 2004 to 2008 (Williams, 2009). Membership in a highly productive research department is one of the best structural predictors of publication productivity (Ramsden, 1994: 219).

[Table 2 about here] 


\section{Results}

During the period 2005-2007, full-time male academics published, on average, 10.5 article equivalents. This was significantly more than females, who published 8.0 article equivalents. By comparison, during the period 1991-1993 males published 8.2 article equivalents, significantly more than females who published 4.6 article equivalents. This represents a general increase in publication productivity of 28 percent for men and 72 percent for women between the two surveys. Gender differences narrowed, with females achieving 76 percent of the male average in 2005-2007, compared to 57 percent in 1991-1993. Gender differences in publication productivity were statistically significant across all publication types in the 1993 data, with women publishing just over half as many authored books ( 0.17 vs. 0.34$)$, edited books ( 0.19 vs. 0.29$)$ and articles (3.38 vs. 5.88 ). Due to the smaller sample and overall reduction in gender differences in the 2007 data, only articles published were significantly different (6.21 vs. 8.28). These results are shown in Table 3.

[Table 3 about here]

When classified into the five academic fields based on the guidelines of UNESCO (1978), publication productivity in the 1993 sample was highest in the natural sciences (8.4 article equivalents), humanities (8.2) and medicine (7.7), significantly higher than in the social sciences (6.2) and technology (5.2) (ANOVA, Games-Howell $t$-test, $p<0.05$ ). There were no significant differences between any academic fields in the 2007 sample, but article equivalents were higher in the technology (10.4), natural sciences (10.3) and humanities (9.9), compared to social sciences (8.7) and medicine (8.3). Had publication productivity been measured based on articles only, gender differences would be partly due to the greater proportion of men in the sciences, where articles are more commmon than books. However, the use of the article equivalents minimises the impact of academic field because books received a heavier weight than articles.

The academic field differences in publication productivity in the 1993 data were probably due to the amalgamation of CAEs into universities in the late 1980s and early 1990s, as teaching-based social science and technology staff were required to immediately become research active. However, gender differences in publishing were consistent across academic fields. Women published significantly fewer article equivalents than men in the same academic field in all cases, except in technology in the 2007 sample and the natural sciences in the 1993 sample. Even within the traditionally female and former CAE discipline of education and teacher training, males published significantly more than females in both samples. Given that differences between academic fields were far smaller than gender differences within fields, the importance of academic field in explaining gender differences in publishing levels is probably minor compared to other factors where women differ significantly from men, such as academic rank, doctorate degree and international research collaboration.

Publication productivity is heavily skewed and highly variable. Most academics publish below the mean and the standard deviation is high. This indicates that a minority of highly productive researchers account for a disproportionate share of total publications. In the 1993 data, the most productive 15 percent of females published 55 percent of female output, while the most productive 15 percent of males published 46 percent of male output. These findings are very similar to the earlier Australian study by Ramsden (1994: 218) where 14 percent of 
all staff accounted for half of all research output. In the 2007 data, the same group accounted for 44 percent of female and 48 percent of male output. Therefore, overall increases in female publication productivity between 1993 and 2007 were associated with a more equitable distribution of female publications.

The reduction in gender differences is largely due to a dramatic increase in female research participation. The proportion of academics publishing at least one article equivalent increased from 86 percent of men and 76 percent of women in 1991-1993, to 92 percent and 91 percent respectively in 2005-2007. The proportion of academics with relatively few publications also became similar for men and women. During 1991-1993, more than half of all women averaged less than three article equivalents, compared to 30 percent of men. During 20052007, 25 percent of women and 23 percent of men were in this category. While the proportion of women publishing at very high levels increased, males remained almost three times more likely to publish 20 or more article equivalents in 2005-2007. When examined by academic field, the proportion of academics in this highly publishing category closely reflected the overall sample distribution. This suggests that the greater frequency of highly publishing males is not primarily due to their location in the scientific disciplines.

Mean article equivalents increased rapidly with academic rank and the smaller percentage of women in higher academic ranks accounted for much of the overall gender differences in publishing. During 1991-1993, publication productivity increased from 2.8 article equivalents at the lowest rank (Level A) to 15.0 article equivalents among professors (Level E). The relationship with rank was even stronger in 2005-2007, increasing from 3.2 to 21.6 article equivalents. Differences between men and women of equal rank are insignificant, except among the lowest rank (Level A) in 1991-1993, where males published significantly more article equivalents than women (4.4 vs. 1.9). These results are very similar to earlier studies which found no gender differences in publishing above Level B (Burton, 1997: 24).

The independent variable summary statistics (Table 1) show that men and women differ in their mean levels for many independent variables. Gender differences across most variables were statistically significant in the 1993 sample in the direction hypothesised as disadvantageous to publication productivity. Gender differences were clearly smaller in the 2007 sample, but men remained significantly more likely to have high academic rank, a doctorate degree, international research collaborators, be married, have children and not have interrupted their career for child or elder care. The Pearson correlation coefficients with article equivalents were broadly similar for men and women, suggesting that the factors affecting publishing differ little by gender.

The separate effect of each independent variable on publication productivity (square root of article equivalents) is indicated in the linear multiple regression results in Table 4 . The 2007 data provided information on 22 independent variables, while the 1993 data was restricted to 12 variables. To improve comparability between data sets, a standard 12 variable and full 22 variable regression model are shown for the 2007 data. Multicolinearity among independent variables was not a concern because bi-variate correlations among the independent variables were low and variance inflation factors reached a maximum of 3.39. The proportion of variation in publication productivity accounted for by the 12 variable model (adjusted Rsquare) was 32 and 42 percent among men and women in the 1993 data, and 44 and 47 percent respectively in the 2007 data. The effect of the ten additional institutional, 
background and family variables available in the 2007 data was minor, with few achieving significance.

\section{[Table 4 about here]}

The work habits variables, particularly academic rank, were clearly the strongest predictors of publication productivity. The number of women reporting a stronger interest in research increased from less than half in the 1993 data, to over two thirds in the 2007 data. However, while having an interest in research was a relatively strong predictor of publication productivity in the 1993 data, it was insignificant in the 2007 data. By contrast, despite an equally dramatic increase in the proportion of female academics with doctorates, holding a doctorate remained consistent in strength and significance across the two samples. One of the most notable changes was the increased importance of international research collaborators. In the 2007 sample, over 90 percent of academics who published at least 10 article equivalents reported international collaborators. This compared with less than half of other academics. International research collaboration showed a uniformly positive effect for men and women in the 2007 data. This contrasted sharply with international conference attendance which was positive only for men in both samples, despite men and women being equally likely to report international conference attendance in the 2007 sample. This suggests that international collaboration is important for all academics, regardless of rank, qualifications or gender, while international conference attendance is positive only for men.

The number of hours spent on research was positively associated with higher publication productivity and the effect was similarly strong for men and women. In the 1993 data, men spent significantly more hours than women on research (17.2 vs. 14.9), which partly explained the overall gender differences in publication productivity. However, gender differences were not statistically significant in the 2007 data. Total weekly hours (not shown in Table 1) were significantly longer for men in the 1993 data (50.2 vs. 48.8), but roughly equal in the 2007 data (49.2 vs. 49.9). Therefore, the number of hours and proportion of time spent on research offered a partial explanation for gender differences in publication productivity during 1991-1993, but not during 2005-2007.

The block of institutional variables generally failed to achieve significance. Administration hours were roughly equal for men and women in both samples and had no effect on publication productivity. Somewhat surprisingly, teaching hours were insignificant as a predictor of publication productivity, despite negative bi-variate correlations with article equivalents. Satisfaction with research funding, institutional facilities and having collegial support for one's research, also showed no effect on publication productivity. Location within one of the two more research intensive university groupings, Go8 and ATN, had a positive effect on publication productivity, but only for women.

The background variables also failed to account for much of the variation in publication productivity. Age exhibited a negative relationship with publication productivity for men in the 1993 data and women in the 2007 data. However, a negative impact of aging on publication productivity can not be inferred from these results due to the cross-sectional nature of the data. The greater proportion of younger staff with doctorates and preferences towards research in the 2007 data, suggests clear generational differences within the samples. The additional marital, family and career interruption variables, available only in the 2007 data, failed to achieve significance for women in the regression analysis. For men, being 
married to a fellow academic showed a positive effect on publication productivity compared to being single or married to a non-academic.

\section{Discussion}

The first two objectives of this study were to quantify the size of gender differences in publication productivity and changes over time. The results suggest an overall improvement in the position of women in research since the early 1990s. The results for the 2005-2007 period showed that women published 24 percent fewer article equivalents than men, compared to 46 percent fewer over the 1991-1993 period. The increase in female publication productivity and overall reduction in gender differences was mostly due to a reduction in the proportion of women with zero or very few publications. The high proportion of low or nonpublishing female academics in the 1993 sample and greater proportion of women with doctorates and research interests in the 2007 sample, probably reflects the integration of formerly teaching-focused CAE staff into research positions and the growing research credentials of younger academics. The more equitable distribution of female publishing in the 2007 sample is an important departure from previous gender-based studies, which have emphasised the overrepresentation of women as non-publishers (Creamer, 1998) and the dominance of a few prolific female publishers (Cole and Zuckerman, 1984). Men and women of equal rank published at similar levels, except among the lowest ranks in the 1993 sample, but the high publishing elite remained overwhelmingly male. These findings are consistent with previous Australian studies (Burton, 1997; Ramsden, 1994).

The third objective of this study was to examine whether the hypothesised determinants of publication productivity operated similarly for men and women. Fox's (1983) and Teodorescu's (2000) clusters of individual background, work habits and institutional variables accounted for a reasonably large proportion of the variability in publication productivity, between 32 and 48 percent. Most variables operated in the same direction for men and women, but there were noticeable differences in the strengths of variables. The strength of academic rank, doctorate degree, international research collaboration and research hours, is illustrative of how research habits and conditions affect publishing, though the relationships may also be reciprocal. Women reported lower levels on these four core variables and differences were statistically significant in all cases, except research hours in the 2007 sample. The stronger effect of academic rank, doctoral degree and institutional location on female publishing in the 2007 sample, also suggests female research opportunities are particularly affected by their structural position and seniority within Australian universities (White, 2003, 2004).

Teaching and administrative loads are frequently reported as a barrier to research (McInnis, 1999; Milem, et al., 2000). Research hours exhibited a consistently positive effect on publication productivity and the significantly fewer hours women spent on research in the 1993 data partly explains differences in publication productivity. While there was support in the 1993 data for gendered patterns in time use, the 2007 data indicated no significant gender differences in the mean number of research, teaching or administrative hours, or their relationship with publication productivity. These findings are consistent with other Australian studies which found no gender differences in assigned teaching loads (Probert, 2005) or classroom teaching hours (McInnis, 1999). The minimal effect of teaching hours on publishing is also consistent with Dever and Morrison's (2008) positive accounts of 
compatibility between teaching and research among highly publishing females. However, the results do not necessarily contradict the claims that women are more likely to become trapped in lower ranked positions with heavier teaching loads (White, 2004). Teaching-only and parttime academics were explicitly excluded from the samples and such academics may include a higher proportion of women. However, the results from the 2007 sample suggest that men and women in combined research and teaching positions spend similar hours on each of the three core academic duties, with comparable effects on publication productivity.

Perhaps the most important finding from this study is the role of international research networks. In the 1993 data, less than half of all women had international research collaborators and the positive effects were evident only for men. Women remained significantly less likely than men to report international research collaborators in the 2007 sample, but the positive effects were equal for men and women. The importance of international research collaboration for female publication productivity is consistent with previous gender-based studies (Kyvik and Teigen, 1996). International collaboration can increase the visibility of academics, their access to large-scale external funding, their attractiveness for future collaborators, and lead to an accumulation of positive reinforcement and advantage (Fox, 1983). The significantly fewer women with international collaborators, supports the assertion the women have weaker international networks and this negatively impacts their publication productivity (Cole and Zuckerman, 1984; Ramsay 1999, in White, 2001: 68).

International conferences offer an opportunity, not just to develop international networks, but also to present research results. Men were significantly more likely to attend international conferences in the 1993 data, but no gender differences were evident in the 2007 data. While this appears to be an encouraging sign of greater gender equality, the positive effects were significant only for men in both samples. One possible reason is that Australian men are almost twice as likely as women to dedicate time to conference organisation and management (Probert, 2005). If women are less involved in organising conferences, women may attend international conferences but fail to benefit from presenting their research to a relevant audience (Kyvik and Larsen, 1994). Even where international conference organisers directly invite Australian women to present their research, responsibilities for young and teenage children prevents some high profile female researchers from accepting their invitations (Probert, 2005).

The unequal division of labour in the household is an intuitive reason for why women lack time and energy for publishing. The results of this study indicate no direct effect of marriage, children or career interruptions for female publication productivity, but a small positive effect of marriage for male productivity. The overall weak effect of the female background variables, compared to work habit variables, is very consistent with a previous American study (Sax, et al., 2002) and Dever and Morrison’s (2009) interviews with highly publishing Australian women. The results may also be due to selectivity factors and lack of detail in the data. Compared to male academics, females are more likely to consider career pressures when deciding about children and marriage (Sonnert and Holton, 1995). Female publication productivity is more directly affected by young children (Kyvik and Teigen, 1996) and women are more likely to have fewer children and be unmarried (Long, et al., 1993). Detail on family decision making and the age of children is not available in the data, but selectivity effects are implied by the significantly higher proportion of female academics who are unmarried and without children. Further, if family responsibilities limit the opportunities for 
women to gain a doctorate or promotion, then the effect of the family variables may have been absorbed by the stronger effects of doctorates and academic rank for females in the 2007 data.

This study has demonstrated that Australian female academics in full-time research and teaching positions have become increasingly similar to their male counterparts in publication productivity and many of the factors affecting publication. However, gender differences remain and the nominal improvements in the research conditions of full-time female academics may mask decreasing research opportunities for women in non-standard positions. Employment flexibility in Australian universities has coincided with increased academic labour market segmentation. Ongoing part-time employees face formal or practical restrictions in promotion (Winchester, et al., 2006), while casual and sessional positions tend to be teaching-based with poorer research prospects (Junor, 2004). Academic labour market segmentation has a disproportionate impact on women since they remain under represented in full-time positions (Probert, 2005). If research is more difficult outside full-time employment, then future studies must investigate whether full-time female academics are an increasingly selective group, successful on the traditional and masculine terms that circumscribe the academic career.

\section{References}

Allen, M. and T. Castleman (2001) 'Fighting the pipeline fallacy', pp. 151-165 in A. Brooks and A. Mackinnon (eds.) Gender and the Restructured University. Buckingham: SRHE and Open University Press.

Asmar, C. (1999) 'Is there a gendered agenda in academia? The research experience of female and male PhD graduates in Australian universities', Higher Education, 38(3): 255-273.

Bell, S. (2010) 'Women in Science: The Persistence of Gender in Australia', Higher Education Management and Policy 22(1): 47-65.

Bell, S., and R. Bentley (2005) Women in research: Discussion paper. Prepared for the Australian Vice-Chancellors, National Colloquium of Senior Women Executives.

Burton, C. (1997) Gender equity in Australian university staffing. Canberra: DETYA.

Carrington, K. and A. Pratt (2003) How far have we come? Gender disparities in the Australian higher education system. Canberra: Department of the Parliamentary Library.

Castleman, T., M. Allen, W. Bastalich and P. Wright (1995) Limited Access: Women's Disadvantage in Higher Education Employment. Melbourne: National Tertiary Education Union.

Coates, H., L. Goedegebuure, J. Van Der Lee and L. Meek (2008) 'The Australian Academic Profession: a first overview', pp. 179-202 Changing Academic Profession in International Comparative and Quantitative Perspectives. Hiroshima: RIHE Hiroshima University. 
Cole, J. and H. Zuckerman (1984) 'The productivity puzzle: persistence and change in patterns in publication of men and women scientists', Advances in Motivation and Achievement 2: 217-258.

Creamer, E. (1998) Assessing faculty publication productivity: Issues of equity. Washington D.C.: ASHE-ERIC.

DEEWR (2008) Review of Australian Higher Education Discussion Paper June 2008. Canberra: DEEWR.

DEEWR (2010) Staff 2010: Selected Higher Education Statistics, Canberra: DEEWR.

Dever, M., Boreham, P., Haynes, M., Kubler, M., Laffan, W., M. Western and K. Behrens (2008) Gender differences in early post-PhD employment in Australian Universities: The influence of PhD experience on women's academic careers: Final report. Brisbane: The University of Queensland Social Research Centre.

Dever, M, and Z. Morrison (2009) 'Women, Research Performance and Work Context'. Tertiary Education and Management 15(1): 49-62.

Fox, K. and R. Milbourne (1999) 'What determines research output of academic economists?', Economic Record 75(3): 256-267.

Fox, M. (1983) 'Publication productivity among scientists: A critical review', Social Studies of Science 13(2): 285-305.

Fox, M. (2005) 'Gender, family characteristics, and publication productivity among scientists', Social Studies of Science 35(1): 131-150.

Fox, M. and S. Mohapatra (2007) 'Social-organizational characteristics of work and publication productivity among academic scientists in doctoral-granting departments', The Journal of Higher Education 78(5): 542-571.

Hartley, N. and A. Dobele (2009) 'Feathers in the Nest: Establishing a Supportive Environment for Women Researchers', Australian Educational Researcher 36(1): 43-58.

Junor, A. (2004) 'Casual university work: choice, risk, inequity and the case for regulation', Economic and Labour Relations Review 14(2): 276-304.

Katz, J. and B. Martin (1997) 'What is research collaboration?', Research policy 26(1): 1-18.

Kyvik, S. (1991) Productivity in academia:Scientific publishing at Norwegian Universities. Oslo: Norwegian University Press.

Kyvik, S. and I. Larsen (1994) 'International contact and research performance', Scientometrics 29(1): 161-172.

Kyvik, S. and M. Teigen (1996) 'Child care, research collaboration, and gender differences in scientific productivity', Science, Technology, and Human Values 21(1): 54-71. 
Lafferty, G. and J. Fleming (2000) 'The Restructuring of Academic Work in Australia:

Power, Management and Gender', British Journal of Sociology of Education 21(2): 257-267.

Long, J. (1990) 'The origins of sex differences in science', Social Forces 68(4): 1297-1316.

Long, J., P. Allison and R. McGinnis (1993) 'Rank advancement in academic careers: Sex differences and the effects of productivity', American Sociological Review 58(5): 703-722.

McInnis, C. (1999) The work roles of academics in Australian universities. Canberra: DETYA.

Milem, J., J. Berger and E. Dey (2000) 'Faculty time allocation: A study of change over twenty years', Journal of Higher Education 71(4): 454-475.

Probert, B. (2005) "I just couldn't fit it in': Gender and unequal outcomes in academic careers', Gender, Work \& Organization 12(1): 50-72.

Ramsden, P. (1994) 'Describing and explaining research productivity', Higher Education 28(2): 207-226.

Sax, L., L. Hagedorn, M. Arredondo and F. DiCrisi (2002) 'Faculty research productivity: exploring the role of gender and family-related factors', Research in Higher Education 43(4): 423-446.

Sheehan, B. and A. Welch (1996) 'The Australian academic profession', pp. 51-94 in P. G. Altbach (ed.), The international academic profession: Portraits from fourteen countries. Princeton: Carnegie Foundation.

Sonnert, G. and G. Holton (1995) Gender differences in science careers: The project access study. New Brunswick: Rutgers University Press

Teodorescu, D. (2000) 'Correlates of Faculty Publication Productivity: A CrossNational Analysis', Higher Education 39(2): 201-222.

UNESCO (1978) Recommendation Concerning the International Standardization of Statistics on Science and Technology, Paris: UNESCO.

White, K. (2001) 'Women in the Professoriate in Australia', International Journal of Organisational Behaviour 3(2): 64-76.

White, K. (2003) 'Women and leadership in higher education in Australia', Tertiary Education and Management 9(1): 45-60.

White, K. (2004) 'The leaking pipeline: Women postgraduate and early career researchers in Australia', Tertiary Education and Management 10(3): 227-241.

Williams, R. (2009) 'Research output of Australian universities: are the newer institutions catching up?', Australian Universities Review 52(1): 32-36. 
Winchester, H., S. Lorenzo, L. Browning and C. Chesterman (2006) 'Academic women's promotions in Australian universities', Employee Relations 28(6): 505-522.

Xie, Y. and K. Shauman (1998) 'Sex differences in research productivity: new evidence about an old puzzle', American Sociological Review 63(6): 847-870. 
Table 1. The number and percentage of full-time academics by rank and gender, 1993 and 2007 samples

\begin{tabular}{|c|c|c|c|c|c|c|c|c|c|c|c|c|}
\hline & \multicolumn{6}{|c|}{1993 Carnegie } & \multicolumn{6}{|c|}{2007 CAP } \\
\hline & \multicolumn{2}{|c|}{ Male } & \multicolumn{2}{|c|}{ Female } & \multicolumn{2}{|c|}{ Total } & \multicolumn{2}{|c|}{ Male } & \multicolumn{2}{|c|}{ Female } & \multicolumn{2}{|c|}{ Total } \\
\hline & $\mathrm{N}$ & $\%$ & $\mathrm{~N}$ & $\%$ & $\mathrm{~N}$ & $\%$ & $\mathrm{~N}$ & $\%$ & $\mathrm{~N}$ & $\%$ & $\mathrm{~N}$ & $\%$ \\
\hline Level A & 31 & 4 & 53 & 16 & 84 & 8 & 20 & 6 & 28 & 10 & 48 & 8 \\
\hline Level B & 219 & 31 & 172 & 53 & 391 & 38 & 107 & 31 & 123 & 42 & 230 & 36 \\
\hline Level C & 245 & 34 & 67 & 20 & 312 & 30 & 94 & 28 & 84 & 29 & 178 & 28 \\
\hline Level D & 130 & 18 & 18 & 6 & 148 & 14 & 63 & 18 & 33 & 11 & 96 & 15 \\
\hline Level E & 84 & 12 & 11 & 3 & 95 & 9 & 55 & 16 & 24 & 8 & 79 & 12 \\
\hline Unknown & 4 & 1 & 6 & 2 & 10 & 1 & 2 & 1 & 0 & 0 & 2 & 0 \\
\hline Total & 713 & 100 & 327 & 100 & 1040 & 100 & 341 & 100 & 292 & 100 & 633 & 100 \\
\hline
\end{tabular}


Table 2. Independent variable description, means and Pearson correlation coefficients with article equivalents

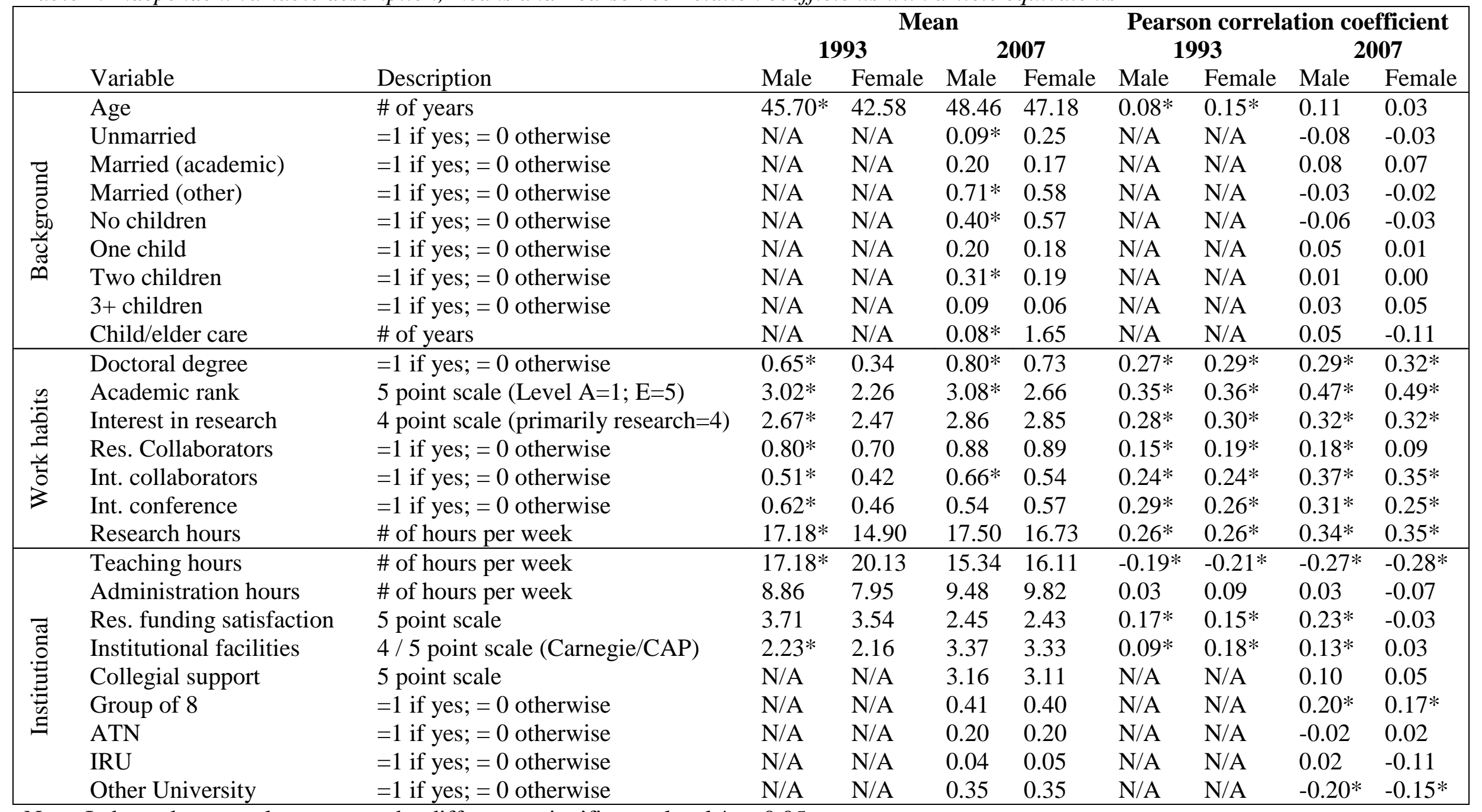

Note: Independent samples $t$-test gender difference, significance level $* p<0.05$ 
Table 3. Mean publications and standard deviation by type and gender, 1991-1993 and 20052007

\begin{tabular}{|l|llll|llll|}
\hline & \multicolumn{3}{|c|}{$1991-1993$} & \multicolumn{3}{c|}{ 2005-2007 } \\
& Male & \multicolumn{2}{|c|}{ Female } & \multicolumn{3}{c|}{ Male } & Female \\
& Mean & S.D. & Mean & S.D. & Mean & S.D. & Mean & S.D. \\
\hline Books authored & $0.34^{*}$ & 0.79 & 0.17 & 0.48 & 0.34 & 0.72 & 0.28 & 0.62 \\
Books edited & $0.29 *$ & 0.86 & 0.19 & 0.65 & 0.24 & 0.68 & 0.17 & 0.54 \\
Articles & $5.88^{*}$ & 7.35 & 3.38 & 5.74 & $8.28^{*}$ & 10.16 & 6.21 & 7.07 \\
Article equiv. & $8.17^{*}$ & 9.33 & 4.63 & 7.08 & $10.47^{*}$ & 11.67 & 7.96 & 8.34 \\
\hline
\end{tabular}

Note: Independent samples $t$-test gender difference, significance level $* p<0.05$ 
Table 4. Linear multiple regression beta weights for publication productivity (square root of article equivalents)

\begin{tabular}{|c|c|c|c|c|c|c|}
\hline & \multicolumn{2}{|c|}{1993 data } & \multicolumn{2}{|c|}{2007 data } & \multicolumn{2}{|c|}{2007 Full model } \\
\hline & Male & Female & Male & Female & Male & Female \\
\hline \multicolumn{7}{|l|}{ Background variables } \\
\hline Age & $-0.08^{+}$ & & & $-0.14^{* *}$ & & $-0.13^{*}$ \\
\hline Married (academic) & N/A & N/A & N/A & N/A & $0.13^{+}$ & \\
\hline Married (other) & N/A & N/A & N/A & N/A & & \\
\hline One child & N/A & N/A & N/A & N/A & & \\
\hline Two children & N/A & N/A & N/A & N/A & & \\
\hline Three or more child. & N/A & N/A & N/A & N/A & & \\
\hline Child/elder care break & N/A & N/A & N/A & N/A & & \\
\hline \multicolumn{7}{|l|}{ Work habits variables } \\
\hline Doctoral degree & $0.13^{* *}$ & $0.20 * *$ & $0.14^{* *}$ & $0.19 * *$ & $0.12^{*}$ & $0.14^{*}$ \\
\hline Academic rank & $0.34 * *$ & $0.29 * *$ & $0.35 * *$ & $0.46^{* *}$ & $0.31 * *$ & $0.48 * *$ \\
\hline Interest in research & $0.14 * *$ & $0.22 * *$ & & & & \\
\hline Research collaborators & & $0.13^{*}$ & & & & \\
\hline Int. Collaborators & $0.11^{* *}$ & & $0.17 * *$ & $0.17 * *$ & $0.18 * *$ & $0.16^{* *}$ \\
\hline Int. Conference & $0.14^{* *}$ & & $0.13^{* *}$ & & $0.11^{*}$ & \\
\hline Research hours & $0.13 * *$ & $0.13^{+}$ & $0.18^{* *}$ & $0.15^{* *}$ & $0.15^{*}$ & $0.16^{*}$ \\
\hline \multicolumn{7}{|l|}{ Institutional variables } \\
\hline \multirow{4}{*}{\multicolumn{7}{|c|}{$\begin{array}{l}\text { Teaching hours } \\
\text { Administration hours } \\
\text { Funding satisfaction } \\
\text { Institutional facilities }\end{array}$}} \\
\hline & & & & & & \\
\hline & & & & & & \\
\hline & & & & & & \\
\hline Collegial support & N/A & N/A & N/A & N/A & & \\
\hline Group of 8 & N/A & N/A & N/A & $\mathrm{N} / \mathrm{A}$ & & $0.13^{*}$ \\
\hline ATN & N/A & N/A & N/A & $\mathrm{N} / \mathrm{A}$ & & $0.10^{+}$ \\
\hline IRU & N/A & N/A & N/A & N/A & & \\
\hline Adjusted R-square & 0.32 & 0.42 & 0.44 & 0.47 & 0.43 & 0.48 \\
\hline $\mathbf{N}$ & 550 & 203 & 317 & 270 & 306 & 244 \\
\hline
\end{tabular}

Note: significance level $* * p<0.01 * p<0.05^{+} p<0.10$ 


\section{University Library}

\section{- M M N E R VA A gateway to Melbourne's research publications}

Minerva Access is the Institutional Repository of The University of Melbourne

Author/s:

Bentley, $\mathrm{P}$

Title:

Gender differences and factors affecting publication productivity among Australian university academics

Date:

2012-03-01

\section{Citation:}

Bentley, P. (2012). Gender differences and factors affecting publication productivity among Australian university academics. JOURNAL OF SOCIOLOGY, 48 (1), pp.85-103. https:// doi.org/10.1177/1440783311411958.

Persistent Link:

http://hdl.handle.net/11343/113915 